\title{
The protective properties of conversion coatings on 1424 alloy upon oxidation under various conditions
}

\author{
A.S. Kariakin, Yu.A. Kuzenkov and S.V. Oleynik* \\ A.N. Frumkin Institute of Physical Chemistry and Electrochemistry, Russian Academy \\ of Sciences, Leninsky pr. 31, Moscow, 119071 Russian Federation \\ *E-mail: osvpkzifh@mail.ru
}

\begin{abstract}
The influence of parameters of chemical oxidation of lithium-containing aluminum alloy 1424 in chromate-free IFHANAL-3 conversion formulation on the properties of the conversion coatings formed was investigated. After standard pretreatment (grinding, etching and desmutting), the alloy samples were oxidized in IFHANAL-3 with addition of Trilon B and benzotriazole. The coatings thus obtained were filled in a solution of the corrosion inhibitor. The protective ability of the conversion coatings (CC) obtained was determined from the length of the passivity domain on the anodic polarization curves in chloride-containing borate buffer. The length of the passivity domain qualitatively correlates with the time of alloy oxidation and, accordingly, with the CC thickness. A decrease in the oxidation temperature affects the weakening of the protective ability of the CC less strongly than a decrease in the $\mathrm{pH}$ of the conversion formulation. It is shown that on repeated use of the conversion formulation, the $\mathrm{CC}$ formed on alloy 1424 has consistently high protective properties. At the same time, the thickness of the coatings even slightly increases due to the accumulation in the oxidation solution of the products of alloy dissolution. Filling of the coatings obtained in solutions containing various amounts of the corrosion inhibitor showed a significant effect on $\mathrm{CC}$ hydration. This is supported by the increase in the specific weight gain of the coating after its filling with an increase of the inhibitor concentration in the filling solution.
\end{abstract}

Key words: aluminum alloys, conversion coatings, filling of coatings, corrosion inhibitor.

Received: February 25, 2019. Published: April 2, 2019

doi: $\underline{10.17675 / 2305-6894-2019-8-2-8}$

\section{Introduction}

In recent decades, lithium has been successfully used as an alloying component in aluminum alloys. Lithium alloying reduces the specific density of alloys and increases their specific strength, so the use of lithium-containing alloys can improve the operating characteristics of structures and devices manufactured from them.

Alloys of the Al-Mg-Li system are highly valued in industry and aircraft industry due to a combination of high modulus of elasticity and low density. Alloys of this series provide a reduction in the mass of structures by $12-25 \%$, while their strength is close to that of alloy D16 (2024) [1]. Alloy 1424 is designed for welded and riveted structures that require maximum weight reduction. However, this alloy, like many lithium-containing 
alloys with various compositions [2-5], has low resistance to pitting corrosion. In view of this, the use of products made of this alloy requires additional protective treatment. One of the simple and cost-effective ways to protect aluminum alloys from corrosion involves the formation of conversion coatings (CC) on their surface by chemical oxidation. Chemical oxidation solutions based on chromates were used for this purpose for a long time, but now their use is limited for environmental reasons. It should also be noted that uneven CC poorly adhering to a substrate are formed on lithium-containing aluminum alloys on treatment in standard chromatic conversion formulation. To replace them, new chromatefree technologies for creating conversion coatings on aluminum alloys were designed [68], including those using IFHANAL-3 $[9,10]$.

Previously, the possibility to obtain chromate-free $\mathrm{CC}$ on lithium-containing aluminum alloys, and in particular, on alloy 1424 [11], in alkaline IFHANAL-3 solutions with various modifying additives and complexing agents was shown. In view of this, in this work we studied the effect of the modes of alloy 1424 oxidation on the protective properties of the coatings.

\section{Experimental}

The conversion coatings were obtained on flat samples $(20 \times 50 \mathrm{~mm})$ of aluminum alloy 1424 (4.6-5.2\% Mg, 1.5-1.8\% Li, 0.4-0.8\% Zn, 0.05\% Mn, 0.04-0.05\% Sc, Al bal.). The samples were treated with sandpaper of different grit, degreased with ethanol, etched for 1 min in $10 \% \mathrm{NaOH}$ solution $\left(t=65-67^{\circ} \mathrm{C}\right)$, washed with hot distilled water, desmutted for 3 min in $50 \% \mathrm{HNO}_{3}$ solution, washed again with water, and dried. After days of aging in a desiccator with $\mathrm{CaCl}_{2}$, the samples were weighed on an analytical balance $( \pm 0.00001 \mathrm{~g})$ and then immersed in the conversion formulation (CF). After oxidation, they were removed from the solution, washed with distilled water, dried in air at room temperature for at least 12 hours and weighed.

Simultaneously with the formation of the $\mathrm{CC}$, the free corrosion potential of the sample $\left(E_{\mathrm{C}}\right)$ was measured versus saturated silver chloride electrode and its value was recalculated to the normal hydrogen electrode scale (NHE). The thickness of the CC was assessed by the mass loss of the samples after 15 min etching in the standard chromatephosphate solution $\left(20 \mathrm{~g} / \mathrm{l} \mathrm{CrO} 3+50 \mathrm{~g} / \mathrm{l} \mathrm{H}_{3} \mathrm{PO}_{4}\right.$ at $\left.t=80^{\circ} \mathrm{C}\right)$. Further, the samples were washed with distilled water, dried for one day and weighed. The thickness of the CC $(\mu \mathrm{m})$ was calculated by the equation (adjusted for the mass loss of non-coated witness samples treated in the same way):

$$
h=\left(m_{0}-m_{\mathrm{r}}\right) / S \times \rho
$$

where $m_{0}$ is the mass of the coated sample, $\mathrm{g} ; m_{\mathrm{r}}$ is the mass of the sample after removal of the coating, $g ; \rho$ is the coating density, $\mathrm{g} / \mathrm{cm}^{3} ; S$ is the area of the CC on the sample, $\mathrm{cm}^{2}$.

Filling (sealing) of the film was carried out by immersion of the samples with the CC for $1 \mathrm{~h}$ in hot distilled water $\left(98-100^{\circ} \mathrm{C}\right)$ without or in the presence of the corrosion inhibitor. 
Anodic polarization curves on electrodes with $\mathrm{CC}$ (working surface $0.5 \mathrm{~cm}^{2}$ ) were obtained in borate buffer solution ( $\mathrm{pH} \mathrm{7.36)}$ containing $0.01 \mathrm{M} \mathrm{NaCl}$ at $t=20 \pm 2^{\circ} \mathrm{C}$. Polarization of electrodes $(1 \mathrm{mV} / \mathrm{s})$ was started from $E_{\mathrm{C}}$ after 10-20 min of exposure in the test solution.

\section{Results and discussion}

In a previous study [11], it was shown that the greatest degree of suppression of pitting corrosion on alloy 1424 is achieved if a coating was formed on it in a solution of IFHANAL-3 with modifying additives of Trilon B and benzotriazole. After filling the coating in a solution of IFKHAN-25 corrosion inhibitor [12], its protective properties increase several-fold. Due to the fact that this coating better protects the alloy from corrosion than other CC obtained in modified IFHANAL-3 solutions [11], it makes sense to consider it in more detail. In order to optimize the technological process of $\mathrm{CC}$ formation, the effect of shortening the oxidation time, temperature and $\mathrm{pH}$ of the oxidizing solution, as well as the concentration of the corrosion inhibitor in the filling solution, on the properties of the resulting coatings was studied.

As can be seen from the plot of the dependence of the coating thickness on the oxidation time (Figure 1), a decrease in the oxidation time of 1424 alloy samples from 50 min to 10 min brings about a linear decrease of the resulting coating thickness from $6.26 \mu \mathrm{m}$ to $0.62 \mu \mathrm{m}$. As a result, the protective properties of these coatings are reduced (Figure 2). For CC obtained in 10 min oxidation, the passivity breakdown potential $\left(E_{\text {pit }}\right)$ amounted to $-0.2 \mathrm{~V}$ and the passivity domain was $E_{\text {pit }}-E_{\mathrm{c}}=0.25 \mathrm{~V}$. These parameters increase with an increase in the oxidation time. Thus, after 30 minutes of oxidation, the passivity domain was as wide as $0.7 \mathrm{~V}$, and after 50 minutes it was $1.6 \mathrm{~V}$ and the breakdown potential was $1.1 \mathrm{~V}$, which is the best result for a coating $6.26 \mu \mathrm{m}$ thick.

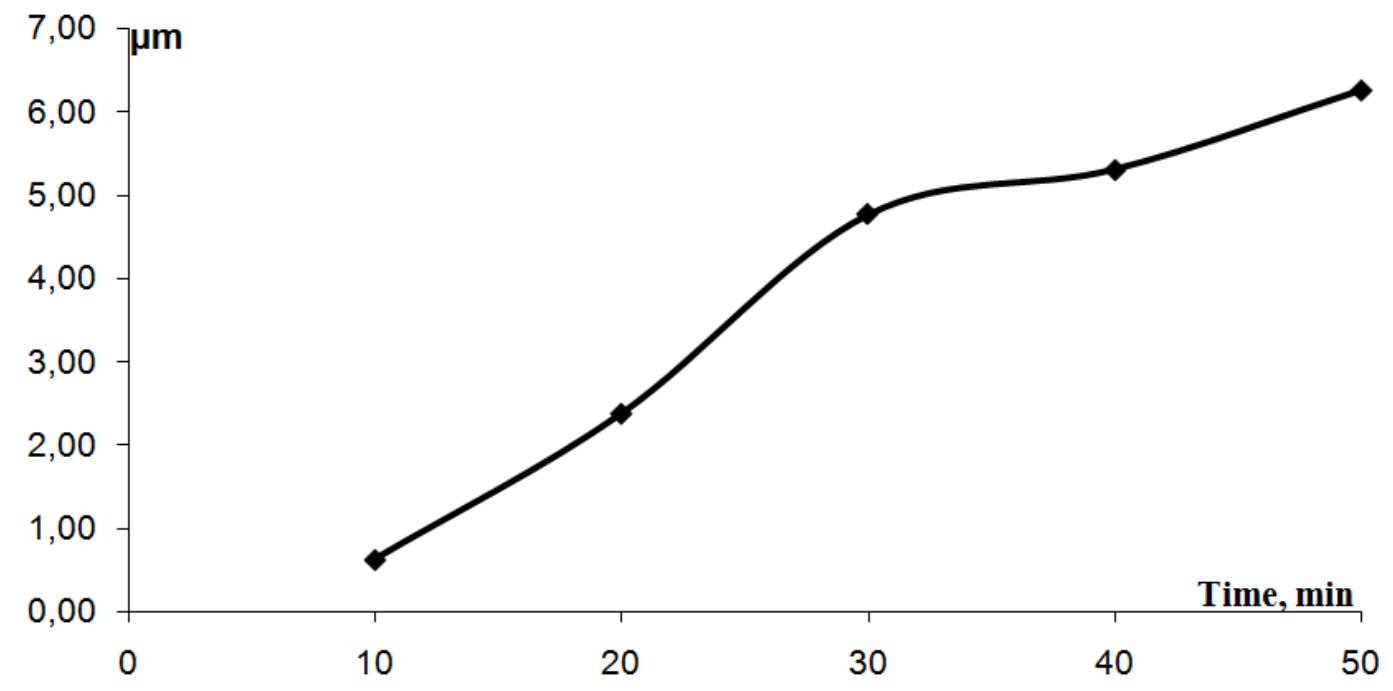

Figure 1. Dependence of coating thickness on oxidation time. 


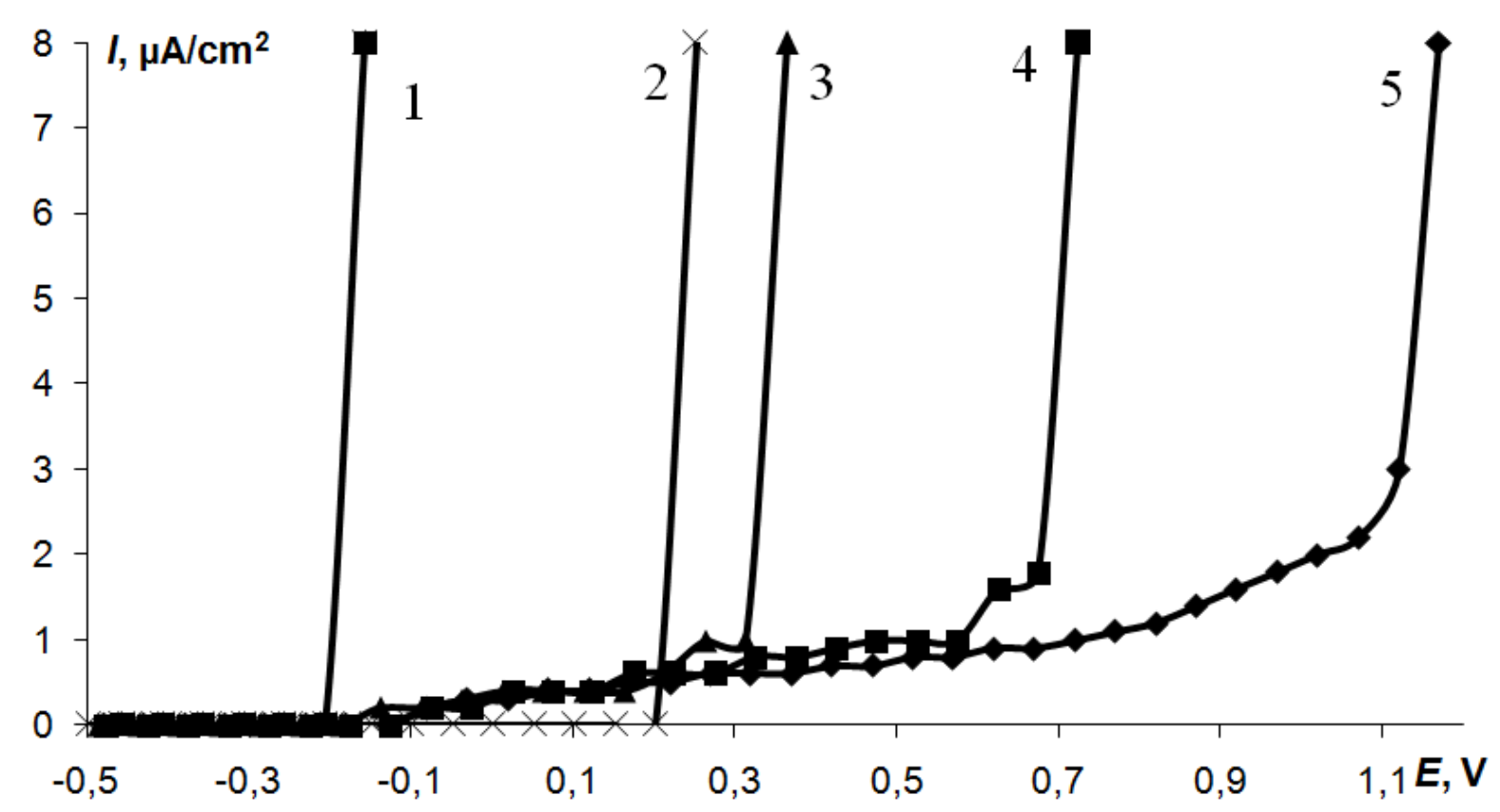

Figure 2. Anodic polarization curves of alloy 1424 with conversion coatings obtained in a solution of IFHANAL-3 + Trilon B + BTA with an increase in the oxidation time, with subsequent filling in the solution of IFHAN-25 corrosion inhibitor: $1-10 \mathrm{~min}, 2-20 \mathrm{~min}$, 3 - $30 \mathrm{~min}, 4-40 \mathrm{~min}, 5-50 \mathrm{~min}$.

Further, the effects of oxidizing solution temperature and $\mathrm{pH}$ on the properties of the resulting $\mathrm{CC}$ were considered. According to polarization measurements (Figure 3), a decrease in the oxidation temperature from $80^{\circ} \mathrm{C}$ to $60^{\circ} \mathrm{C}$ at $\mathrm{pH} 12.2$ reduces the $E_{\text {pit }}$ of the $\mathrm{CC}$ in chloride solution by $0.4 \mathrm{~V}$. Considering that the thickness of these coatings changes only a little, the reduction in their resistance to pit formation is probably related to changes in the structure of the coating. Oxidation of the alloy at $\mathrm{pH}=11.9$ and $t=80^{\circ} \mathrm{C}$ also shifts the $E_{\text {pit }}$ of the $\mathrm{CC}$ to $0.4 \mathrm{~V}$ in the negative direction (the passivity domain is $1.4 \mathrm{~V}$ ). At a lower oxidation temperature, the $E_{\text {pit }}$ of the $\mathrm{CC}$ on the alloy approaches that of a noncoated sample. In this case, the decrease in the protective properties of the coating is due not only to the deterioration of the coating structure (increased defectiveness) but also to their thinning to 4.2 microns.

The stability of the properties of the coatings obtained upon repeated use of the conversion formulation was studied at the optimum parameters of oxidation $\left(50 \mathrm{~min}, 80^{\circ} \mathrm{C}\right.$ and $\mathrm{pH}$ 12.2). As one can see from the plot (Figure 4), the protective properties of the coatings remain at a high level after three oxidation treatments in the same solution, although the thickness of the coatings increases slightly from one oxidation to another, apparently due to the accumulation of the alloy dissolution products in the solution. 


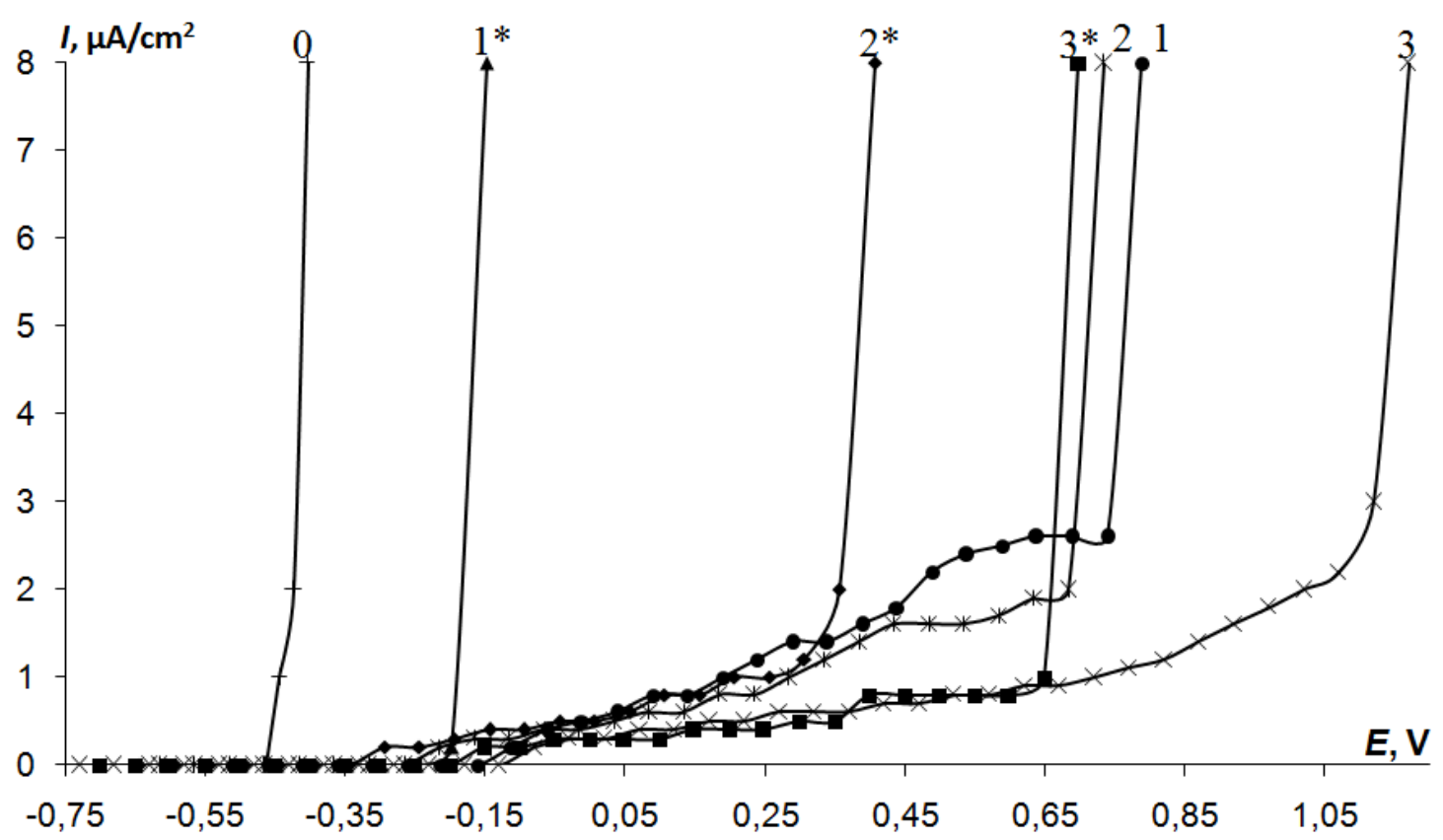

Figure 3. Anodic polarization curves of alloy 1424 with conversion coatings obtained in a solution of IFHANAL-3 + Trilon B + BTA upon reducing the oxidation temperature and solution $\mathrm{pH}$ to $11.9^{*}$, with subsequent filling in the solution of IFHAN-25 corrosion inhibitor: 0 - without a coating, $1^{*}-60^{\circ} \mathrm{C}(4.2 \mu \mathrm{m}), 2^{*}-70^{\circ} \mathrm{C}(5.6 \mu \mathrm{m}), 3^{*}-80^{\circ} \mathrm{C}(6 \mu \mathrm{m}), 1-$ $60^{\circ} \mathrm{C}(5.8 \mu \mathrm{m}), 2-70^{\circ} \mathrm{C}(6 \mu \mathrm{m}), 3-80^{\circ} \mathrm{C}(6.2 \mu \mathrm{m})$.

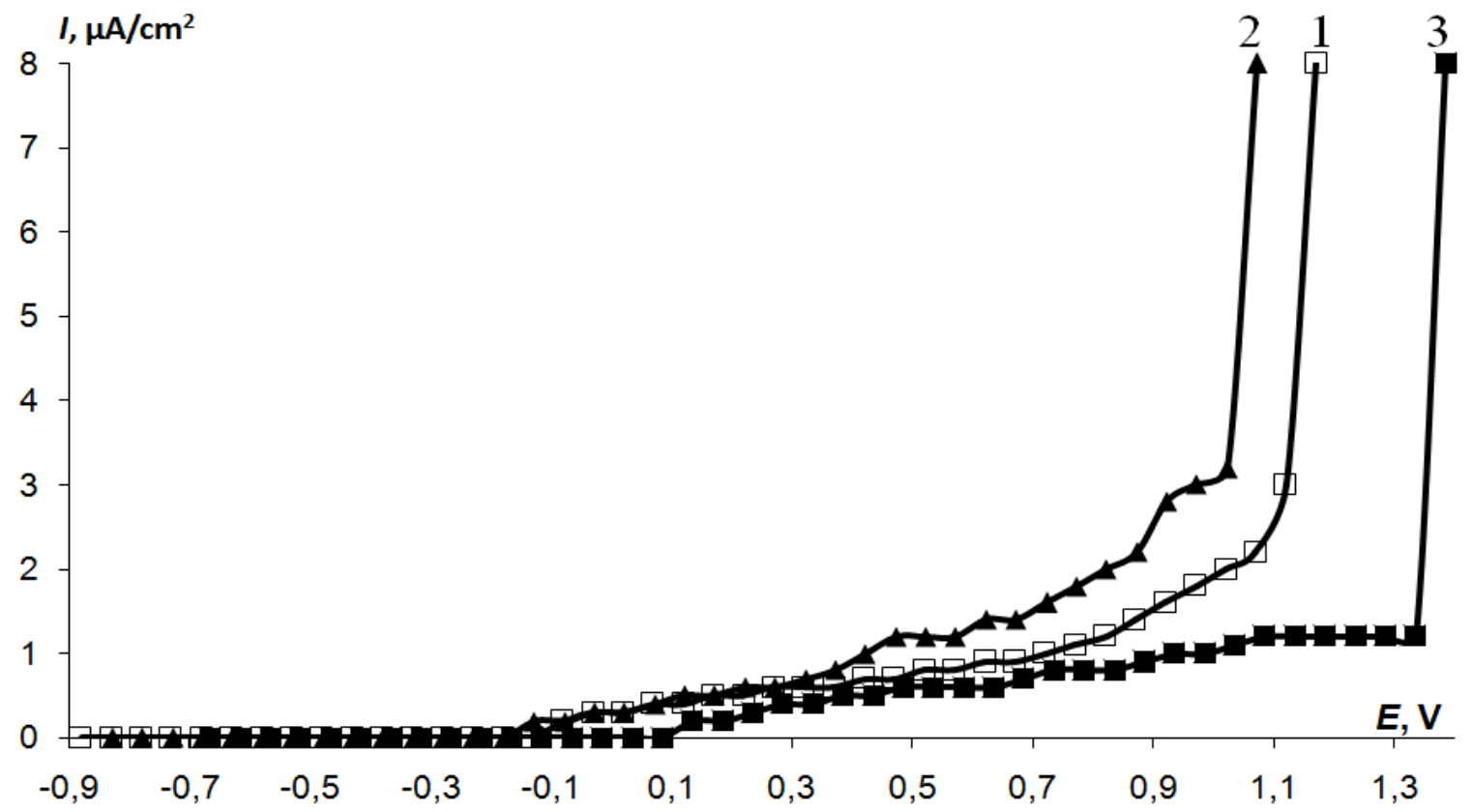

Figure 4. Anodic polarization curves of alloy 1424 with conversion coatings obtained in a solution of IFHANAL-3 + Trilon B + BTA with repeated use of the conversion formulation, with subsequent filling in the solution of IFHAN-25 corrosion inhibitor: 1 - first oxidation $(6.2 \mu \mathrm{m}), 2$ - second oxidation $(7.8 \mu \mathrm{m}), 3$ - third oxidation $(7.7 \mu \mathrm{m})$. 
Owing to the fact that a significant contribution to the increase in the protective properties of the $\mathrm{CC}$ is made by filling in a corrosion inhibitor solution, it was of considerable interest to study the effect of its concentration on the properties of the coatings. In fact, one can see from the polarization curves in Figure 5 that after three parallel fillings in $1 \mathrm{~g} / 1$ IFKHAN-25 solution, the protective properties of the coatings do not change and the value of the passivity domain is consistently high. On the other hand, the protective properties of the $\mathrm{CC}$ are significantly reduced at inhibitor concentrations of 0.5 and $0.25 \mathrm{~g} / \mathrm{l}$ in the filling solution. Apparently, this is due not only to a decrease in the adsorption of the corrosion inhibitor, but also, as previously shown [13], to its participation in the process of filling/hydration of the CC. This is supported by a decrease in the specific weight gain of the coating after its filling with a decrease in the inhibitor concentration in the filling solution. In fact, after filling the samples in IFHAN-25 solutions with concentrations of $1,0.5$ and $0.25 \mathrm{~g} / \mathrm{l}$, their mass increased by $0.04 \mathrm{mg} / \mathrm{cm}^{2}, 0.02 \mathrm{mg} / \mathrm{cm}^{2}$ and $0.006 \mathrm{mg} / \mathrm{cm}^{2}$, respectively. Thus, the hydration of the coating initiated by the corrosion inhibitor can change its structure and protective properties.

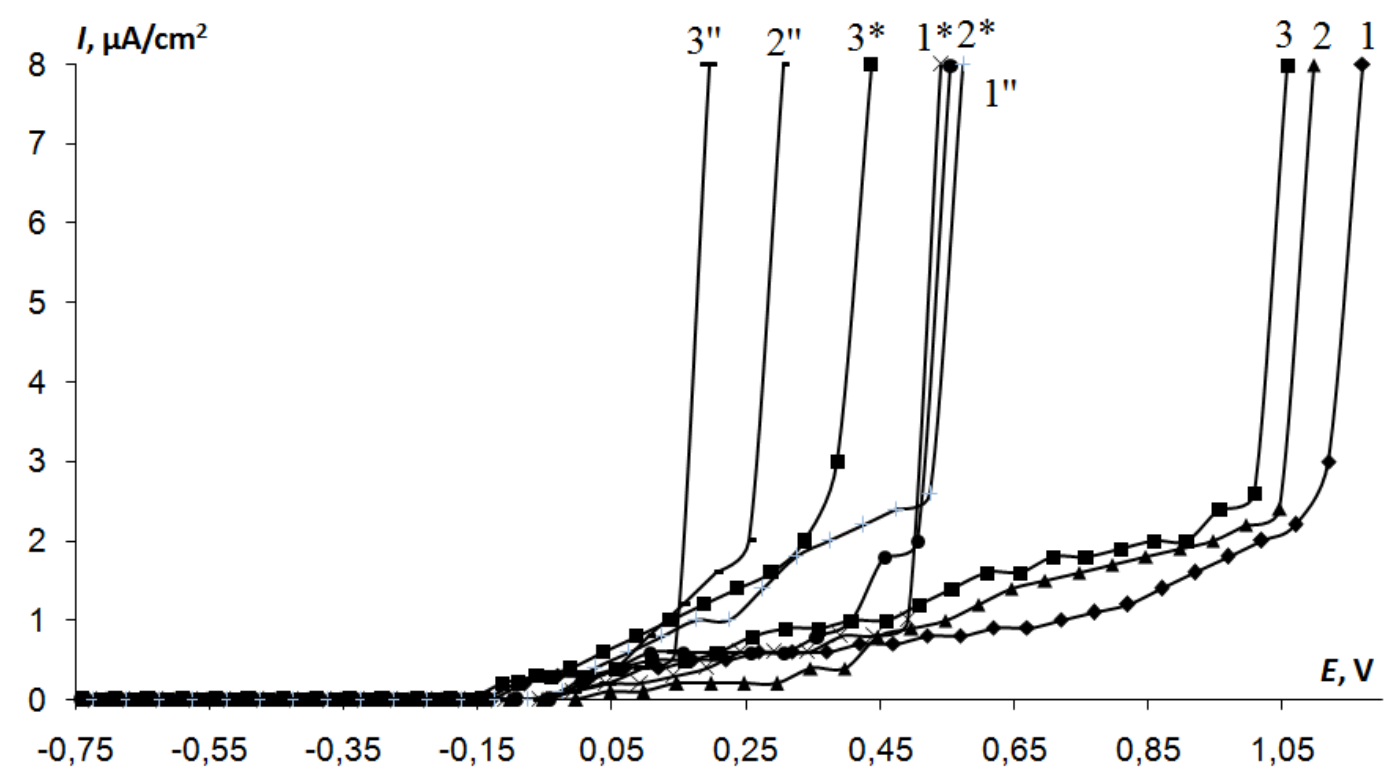

Figure 5. Anodic polarization curves of alloy 1424 with conversion coatings obtained in a solution of IFHANAL-3 + Trilon B + BTA with repeated filling in one solution of IFHAN-25 corrosion inhibitor with a concentration of $1 \mathrm{~g} / \mathrm{l}, 0.5 \mathrm{~g} / \mathrm{l}^{*}, 0.25 \mathrm{~g} / \mathrm{l}^{\prime \prime}: 1$ - first filling, 2 - second filling, 3 - third filling.

\section{Conclusions}

Optimization of the conditions of 1424 alloy oxidation in chromate-free IFHANAL-3 conversion formulation has shown that in the temperature range of $60-80^{\circ} \mathrm{C}$, conversion coating with high resistance to pitting corrosion in chloride environments formed. The main contribution to the corrosion resistance of such coatings is made by filling in IFKHAN-25 corrosion inhibitor solutions. 


\section{References}

1. I.N. Fridliander, Aluminum alloys with lithium and magnesium, Metallurgy and heat treatment of metals, 2003, no. 9, 13-16 (in Russian).

2. J.A. Moreto, C.E. B.Marino, W.W. Bose Filho, L.A. Rocha and J.C.S. Fernandes, SVET, SKP and EIS study of the corrosion behaviour of high strength $\mathrm{Al}$ and $\mathrm{Al}-\mathrm{Li}$ alloys used in aircraft fabrication, Corros. Sci., 2014, 84, no. 7, 30-41.

3. R.G. Buchheit, J.P. Moran and G.E. Stoner, Electrochemical Behavior of the T1 $\left(\mathrm{Al}_{2} \mathrm{CuLi}\right)$ Intermetallic Compound and Its Role in Localized Corrosion of $\mathrm{Al}-2 \% \mathrm{Li}-$ 3\% Cu Alloys, Corrosion, 1994, 50, no. 2, 120-130.

4. K.S. Ghosh, S. Mukhopadhyay, B. Mishra and B. Konar, Study of aging and electrochemical behaviour of Al-Li-Cu-Mg alloys, Mater. Corros., 2013, 64, no. 10, 890-901.

5. A. Balbo, A. Frignani, V. Grassi and F. Zucchi, Corrosion inhibition by anionic surfactants of AA2198 Li-containing aluminum alloy in chloride solutions, Corros. Sci., 2013, 73, no. 8, 80-88.

6. D.K. Heller, W.G. Fahrenholtz and M.J. O'Keefe, Chemical and structural analyses of subsurface crevices formed during spontaneous deposition of cerium-based conversion coatings, Mater. Charact., 2011, 62, no. 11, 1071-1075.

7. P.S. Coloma, U. Izagirre, Y. Belaustegi, J.B. Jorcin, F.J. Cano and N. Lapena, Chromium-free conversion coatings based on inorganic salts $(\mathrm{Zr} / \mathrm{Ti} / \mathrm{Mn} / \mathrm{Mo})$ for aluminum alloys used in aircraft applications, Appl. Surf. Sci., 2015, 345, 24-35.

8. C.S. Liang, Z.F. Lv, Y.L. Zhu, S.A. Xu and H. Wang, Protection of aluminum foil AA8021 by molybdate-based conversion coatings, Appl. Surf. Sci., 2014, 288, no. 1, 497-502.

9. Yu.A. Kuzenkov, S.V. Oleynik and A.S. Koriakin, Modifying chromate-free IFHANAL-3 conversion solution for the production of coatings on aluminum alloy B95T2, Korroz.: mater., zashch., 2016, no. 9, 34-39 (in Russian).

10. Yu.A. Kuzenkov, S.V. Oleynik and A.S. Koriakin, Influence of modifying additives on the protective properties of conversion coatings IFHANAL-3 on D16 aluminum alloy, Korroz.: mater., zashch., 2016, no. 8, 42 (in Russian).

11. Yu.A. Kuzenkov, S.V. Oleynik, A.S. Koriakin and V.L. Vojtitskij, Protective cromatefree conversion coatings on aluminum alloy 1424, Korroz.: mater., zashch., 2019, no. 1, 27-32 (in Russian).

12. Yu.I. Kuznetsov, Organic corrosion inhibitors: where are we now? A review. Part I. Adsorption, Int. J. Corros. Scale Inhib., 2015, 4, no. 4, 284-310. doi: 10.17675/23056894-2015-4-4-1

13. Yu.A. Kuzenkov and S.V. Oleynik, The structure and protective properties of IFHANAL conversion coatings on aluminum alloys, Int. J. Corros. Scale Inhib., 2018, no. 4, 673-682. 